\title{
Produção Escrita no Ensino Médio: fundamentos para o trabalho com o texto argumentativo
}

\author{
Lívia SUASSUNA* \\ Albaneide de Souza CAMPOS**
}

\begin{abstract}
* Doutora (2004) em Linguística pela Universidade Estadual de Campinas (Unicamp). Professora Doutora Associada IV da Universidade Federal de Pernambuco (UFPE). Contato: livia.suassuna@ufpe.br.

** Mestra (2012) em Educação pela Universidade Federal de Pernambuco (UFPE). Professora Colaboradora da Universidade de Pernambuco (UPE). Contato: albaneide.campos@upe.br.
\end{abstract}

\begin{abstract}
Resumo:
Neste artigo, de caráter exploratório e descritivo, buscou-se levantar reflexões sobre o trabalho com o texto argumentativo em aulas de língua portuguesa no ensino médio. Do ponto de vista teórico, a argumentação é entendida aqui como uma ação de linguagem essencialmente dialógica, que tem por objetivo persuadir os interlocutores acerca de ideias expostas e defendidas (GREGOLIN, 1993; BRETON, 2003; PERELMAN; OLBRECHTS-TYTECA, 2005). Para a realização do trabalho, partiu-se do levantamento de alguns estudos empíricos (CONCEIÇÃO, 2002; CRUZ, 2008; RIOLFI; IGREJA, 2010; CAMPOS, 2012) cujos objetos de pesquisa se relacionam diretamente com a produção de textos escritos no contexto escolar. Procurou-se, com isso, questionar/ problematizar procedimentos didáticos utilizados por professores no ensino da argumentação. Em seguida, por meio da análise de dois textos dissertativo-argumentativos produzidos por estudantes de uma escola pública da rede estadual de Pernambuco, são sugeridos encaminhamentos pedagógicos que podem favorecer a compreensão e o uso dos processos e recursos linguístico-discursivos necessários à argumentação. $\mathrm{Na}$ conclusão, reforça-se a tese de que, para a produção de textos argumentativos, o aluno precisa valer-se de algumas habilidades e estratégias específicas que, adequadamente trabalhadas no ensino, garantam-lhe o direito de dizer e de fazer-se ouvido.
\end{abstract}

\section{Palavras-chave:}

Produção escrita. Texto argumentativo. Ensino Médio.

Signum: Estudos da Linguagem, Londrina, v. 23, n. 2, p. 84-99, ago. 2020

Recebido em: 14/05/2020

Aceito em: 14/07/2020 


\title{
Produção Escrita no Ensino Médio: fundamentos para o trabalho com o texto argumentativo
}

\author{
Lívia Suassuna; Albaneide de Souza Campos
}

\section{ConSIDERAÇões INICIAIS}

Neste artigo, tratamos da abordagem do texto argumentativo escrito no ensino médio, motivadas por duas questões centrais, levantadas a partir de nossas práticas de orientadoras de estágio em cursos de licenciatura e formadoras de professores de língua portuguesa, assim como de pesquisas a respeito desse mesmo tema. A primeira dessas questões é a baixa frequência do trabalho sistemático com a escrita em sala de aula e a segunda é a redução da complexidade do texto argumentativo, que, nessa perspectiva, passa a ser ensinado aos aprendizes como sendo resultado de esquemas fixos de desenvolvimento.

Para o desenvolvimento do estudo, adotamos a concepção de texto como sendo uma

manifestação verbal, constituída de elementos linguísticos de diversas ordens, selecionados e dispostos de acordo com as virtualidades que cada língua põe à disposição dos falantes no curso de uma atividade verbal, de modo a facultar aos interactantes não apenas a produção de sentidos, como a fundear a própria interação como prática sociocultural (KOCH, 2011, p. 31).

De modo semelhante, concebemos a argumentação como uma ação de linguagem essencialmente dialógica, que tem por objetivo persuadir os interlocutores acerca de ideias expostas e defendidas (GREGOLIN, 1993; BRETON, 2003; PERELMAN; OLBRECHTS-TYTECA, 2005).

Sustentadas nesses conceitos de texto e argumentação, começaremos pela apresentação de alguns estudos que problematizam práticas de ensino da escrita e da argumentação. Na sequência, procuraremos caracterizar o texto argumentativo, ao tempo em que colocamos os desafios que seu modo de funcionamento implica para o processo de ensino-aprendizagem. Em terceiro lugar, traremos alguns fundamentos para o tratamento da escrita na escola, tentando demonstrar sua imprescindibilidade quando se trata de ensinar e aprender a argumentar por escrito. Por fim, mostraremos dois textos argumentativos produzidos por dois alunos do ensino médio de uma escola pública da rede estadual de ensino de Pernambuco e indicaremos procedimentos didáticos que poderiam ser adotados a partir deles, na perspectiva dos fundamentos teóricos e metodológicos expostos anteriormente.

\section{Produção Textual no Contexto Escolar: problematizando algumas práticas no ENSINO MÉDIO}

Cruz (2008) vê na concepção de linguagem como forma de interação entre sujeitos a base para um ensino-aprendizagem significativo da produção de texto. Ela destaca que os interlocutores de um processo interativo são sujeitos sociais entre os quais se constroem vínculos e compromissos, havendo, dessa forma, uma estreita relação entre linguagem, sociedade e cultura. A autora afirma ainda que a produção de sentidos por meio da linguagem resulta de um processo complexo e que o discurso é produzido a partir de determinadas condições (é situado, portanto). Tendo isso em vista, analisou textos escritos por alunos da educação básica e 
constatou que eles eram desenvolvidos conforme um esquema rígido, resultando em discursos homogeneizados e artificiais. Diante desse achado, concluiu que constitui um desafio para a escola levar os alunos a estabelecer por meio da escrita relações dialógicas efetivas com seus interlocutores, num determinado contexto de produção discursiva.

Um segundo estudo relevante para nossa discussão foi desenvolvido por Riolfi e Igreja (2010), que concluíram, em sua pesquisa, que o ensino do texto dissertativo tem sido negligenciado. Após análise de um conjunto significativo de aulas ministradas no ensino médio, viram que apenas $6 \%$ do tempo dessas aulas foram dedicados ao trabalho com textos dessa natureza. Observaram também que: (a) eram raros os momentos de reflexão antes da produção dos textos pelos alunos; (b) as aulas documentadas seguiam um modelo básico, sendo constituídas por dois momentos - a exposição do conteúdo pelo professor e a solicitação da escrita; (c) atividades de revisão coletiva e reescrita praticamente inexistiam.

Com relação às estratégias didáticas utilizadas pelos docentes para o ensino da escrita do texto dissertativo, as três mais frequentes foram, por ordem: (a) sequência didática específica para a escrita da dissertação; (b) escrita isolada de um texto dissertativo a partir de um tema; (c) cópia no quadro de um apontamento a respeito da estrutura do texto dissertativo, seguida de exposição oral pelo professor.

No que diz respeito às produções dos discentes, foram encontrados três grandes tipos de problemas: (a) desconhecimento das características estruturais da dissertação; (b) desconhecimento dos pré-requisitos para a articulação lógica dos segmentos e falta da noção de conjunto textual; (c) precariedade de recursos para a construção da tese ou para sua sustentação. Nesse terceiro caso em particular, foram verificados precário conhecimento enciclopédico, dificuldade de cálculo do efeito de sentido do texto e dificuldade de selecionar, organizar e hierarquizar argumentos que pudessem agregar potencial argumentativo às produções.

Problemas no tratamento da escrita no âmbito da escola também foram identificados por Conceição (2002), que atentou, de forma mais específica, para os procedimentos de avaliação adotados pelos docentes. Além da preocupante ausência da escrita nas aulas de português, essa autora constatou uma supervalorização da nota, que, em geral, era atribuída de forma inconsistente. A correção costumava-se limitar à conferência de erros visíveis na superfície textual, e praticamente não havia retorno da produção ao aluno, na forma de discussão, revisão e reescrita individual ou coletiva. Nas poucas vezes em que ocorreu a reescrita, esta pareceu uma atividade desprovida de sentido, uma vez que não eram estabelecidos critérios claros e consistentes de avaliação. Outro fator que dificultava a revisão e a reescrita é que os comentários tecidos pelos docentes eram vagos e imprecisos, não podendo, por isso, funcionar como um referencial para os alunos.

Investigando possíveis relações entre o ensino da argumentação e a aprendizagem dos alunos, Campos (2012) observou que, na maioria das situações de sala de aula, solicita-se apenas a escrita da dissertação argumentativa, assim definida por Xavier (2010, p. 7):

trata-se de um gênero textual específico que circula em várias instituições sociais, entre elas a escola e a universidade, cujas características formais e funcionais permitem ao seu usuário demonstrar o domínio de certas habilidades linguísticas e intelectuais. Através de uma dissertação argumentativa, o autor procura convencer seu leitor a adotar uma posição (filosófica, política ou ideológica), mudar um comportamento (estético, ético ou moral) ou aceitar um princípio científico como universal.

Outra prática recorrente é a proposta de escrita do texto argumentativo a partir de um debate oral sobre a temática a ser abordada no texto. Ao término do debate, é solicitada aos alunos a escrita da dissertação, pressupondo-se que aquilo que é explicitado oralmente será, automaticamente, apresentado na escrita. Em termos de avaliação, Campos (2012) verificou que em geral não são feitas considerações sobre as produções dos alunos e também não lhes é solicitada a retomada/reescrita das dissertações. 
Para encerrar este item, citamos um estudo de Menegassi e Gasparotto (2016) sobre a importância do trabalho de revisão e reescrita, no qual afirmam que o professor tem pela frente um grande desafio: desenvolver em seus alunos habilidades discursivas que lhes permitam produzir textos pertinentes, que não apenas atendam à estrutura do gênero textual proposto, mas que apresentem um discurso coerente e significativo, tendo em vista a finalidade social dessa produção.

A seguir, como já anunciado, teceremos considerações acerca do texto argumentativo.

\section{O Texto Argumentativo: natureza, estrutura e desafios para o ensino}

A argumentação é uma ação de linguagem que se realiza já nos anos iniciais de nossas vidas. Argumentamos tanto em situações mais usuais (quando defendemos nosso ponto de vista em conversas familiares) quanto em situações mais formais (ao participarmos como candidatos em seleções de estudo, trabalho ou na ocorrência de debates regrados, por exemplo).

Podemos afirmar que argumentar constitui uma atividade discursiva por meio da qual levamos o nosso interlocutor a uma mudança de opinião ou à adesão às nossas teses (PERELMAN; OLBRECHTSTYTECA, 2005) e, nessa perspectiva, vários estudiosos da linguagem compreendem o ato de argumentar como possibilidade de inserção social.

É o caso de Leal e Morais (2006, p. 8), que, ao justificarem a escolha da produção de textos de opinião na escola como tema de pesquisa, apontam a argumentação como "uma atividade socialmente relevante que permeia a vida dos indivíduos em todas as esferas da sociedade", na medida em que a defesa de pontos de vista constitui um aspecto fundamental da autonomia dos sujeitos.

Breton (2003), compartilhando a ideia do papel essencial que a argumentação pode exercer na vida dos indivíduos, considera-a como uma prática inerente à comunicação humana e assevera que, à medida que o homem se identifica com uma palavra, com um ponto de vista próprio sobre o mundo no qual está inserido, pratica argumentação.

Em Pécora (1999, p. 88), encontramos a seguinte afirmação: “o sentido do termo argumentação já não se refere apenas a um tipo particular de emprego verbal, mas sobretudo a uma propriedade fundamental para a caracterização da linguagem como discurso".

Perelman e Olbrechts-Tyteca (2005), nessa mesma linha, registram:

Apenas a existência de uma argumentação, que não seja nem coerciva nem arbitrária, confere um sentido à liberdade bumana, condição de exercício de uma escolha racional. Se a liberdade fosse apenas adesão necessária a uma ordem natural previamente dada, excluiria qualquer possibilidade de escolha; se o exercício da liberdade não fosse fundamentado em razões, toda escolha seria irracional e se reduziria a uma decisão arbitrária atuando num vazio intelectual (p. 581, grifo nosso).

Esses mesmos autores enfatizam ainda que o poder de deliberar e de argumentar é um sinal distintivo da linguagem humana.

Portanto, a argumentação é "o resultado textual de uma combinação entre diferentes componentes, que exige do sujeito que argumenta construir [...] uma explicação, recorrendo a experiências individuais e sociais, num quadro espacial e temporal de uma situação persuasiva (KOCH; ELIAS, 2017, p. 24).

Essa ação de linguagem necessita, porém, de algumas condições básicas para sua ocorrência: a) existência de um tema passível de debate (LEAL; MORAIS, 2006) ou de situações sociais controversas, mas admissíveis (SOUZA, 2003); b) existência de uma ideia a ser defendida (proposição, declaração, tese); c) proposições que justifiquem ou refutem a declaração (através de evidências, justificativas, contra-argumentação) (LEAL; MORAIS); d) um antagonista/opositor, que pode ser real ou virtual (LEAL; MORAIS). 
São essas mesmas condições que atribuem ao texto argumentativo a seguinte caracterização: é um texto que compreende a apresentação de uma tese a ser defendida por meio de argumentos, com o objetivo de fundamentar e validar o que está sendo proposto pelo locutor/autor do texto até chegar-se a uma conclusão/ resposta ${ }^{1}$. Por meio dessas estratégias, o produtor do texto busca fazer com que seu texto tenha consistência, de forma a conseguir a adesão do seu auditório. O texto argumentativo, portanto, tem seu conteúdo revelado por um processo que implica sucessivas regulações, fazendo as ideias nele defendidas serem construídas, reconstruídas, analisadas e organizadas, de acordo com a demanda de interação, com vistas a conseguir o assentimento do interlocutor (CITELLI, 1994).

Do ponto de vista da escrita, a argumentação é um texto que se forma pela conjugação de dados que se articulam, geralmente, através de conectivos, de conjunções e de formas diversificadas usadas na sustentação, refutação ou negociação dos pontos de vista ou teses apresentados.

Para Perelman e Olbrechts-Tyteca (2005), “uma argumentação eficaz é a que consegue aumentar essa intensidade de adesão, de forma que se desencadeie nos ouvintes a ação pretendida (ação positiva ou abstenção) ou, pelo menos, se crie neles uma disposição para a ação, que se manifestará no momento oportuno" (p. 50).

Nesses termos, esses autores defendem que toda argumentação pressupõe a existência de um contato intelectual e apresentam a noção de auditório como o conjunto daqueles que o orador quer influenciar com sua argumentação. Ainda segundo eles, a ideia de auditório é "imediatamente evocada assim que se pensa num discurso" (PERELMAN; OLBRECHTS-TYTECA, 2005, p. 7). Assim, mudando o auditório, a argumentação muda de aspecto. Sobre a noção de auditório, Breton (2003) acrescenta que o auditório que o orador quer convencer a aderir à opinião proposta pode se constituir numa pessoa, num público, num conjunto de públicos ou, em um caso mais extremo, no próprio orador, quando ele objetiva se autoconvencer.

Riolfi e Igreja (2010) comungam dessas afirmações e consideram que, para quem se propõe a escrever um texto dissertativo, existe a necessidade de buscar conhecer o público ao qual se dirige, para que possa apoiar-se em argumentos que não necessariamente correspondam às suas convicções. A argumentação requer, portanto, que o indivíduo lance mão de algumas estratégias linguístico-discursivas que têm o papel de desenvolver um debate de forma ordenada e coerente, visando à modificação da opinião de seu interlocutor. Nesse sentido é que se entende que, para argumentar, faz-se necessário ir além da pessoalidade por meio de um percurso no qual, em grande medida, a educação formal tem um papel fundamental. Ou seja: segundo Riolfi e Igreja, as habilidades requeridas na produção do texto argumentativo escrito não são inatas; ao contrário, devem ser ensinadas pelo professor de língua portuguesa de forma explícita e deliberada.

Ora, se assumimos a ideia de que a argumentação não se faz de qualquer forma e de que "é preciso alguma qualidade para tomar a palavra e ser ouvido” (PERELMAN; OLBRECHTS-TYTECA, 2005, p. 21), compreendemos que as práticas pedagógicas ou os encaminhamentos didáticos adotados pelo professor de língua materna podem contribuir para a construção de textos argumentativos escritos pelos alunos, uma vez que consideramos o professor como "mediador entre o objeto de estudos (no caso, o texto) e a aprendizagem que vai se concretizando nas atividades de sala de aula" (GERALDI, 2003, p. 112). É desafio e papel, pois, da escola levar o aluno a estabelecer uma relação dialógica com seu interlocutor num determinado contexto de produção.

Do ponto de vista social e tendo por base as afirmações já apresentadas, podemos dizer que a argumentação é uma ação frequente nas nossas relações cotidianas, mas somente isso não garante que possamos

\footnotetext{
${ }^{1}$ Os argumentos, segundo Savioli e Fiorin (2001), não são necessariamente uma prova de verdade. Trata-se antes de um recurso de natureza linguística e discursiva destinado a levar o interlocutor a aceitar os pontos de vista daquele que fala e se constroem a partir dos conhecimentos prévios e experiências sócio-histórico-culturais dos produtores de texto.
} 
desenvolvê-la bem em qualquer situação comunicativa. Existem estratégias discursivas e linguísticas necessárias ao desenvolvimento de um texto argumentativo que precisam ser ensinadas. Entendemos, portanto, a escola e a aula de língua portuguesa como espaço e momento privilegiados para o estudo/ensino do texto argumentativo.

Buscando construir um contraponto aos problemas atinentes ao tratamento da escrita argumentativa na escola e com base na caracterização que fizemos do texto argumentativo, traremos, no próximo item, alguns princípios que julgamos relevantes para o ensino-aprendizagem da escrita em geral e do texto argumentativo em particular.

\section{Princípios Téórico-Metodológicos para o Encaminhamento da Produção Escrita NA EsCOLA}

Num estudo intitulado O Desenvolvimento do Conhecimento Linguístico-Discursivo: o que se aprende quando se aprende a escrever?, Costa Val (2009) sustenta que há um conhecimento linguístico-discursivo específico a se desenvolver quando se aprende a escrever, dado, inclusive, que a escrita se realiza dentro de determinadas condições de produção. Assim, o professor de português teria o papel de conduzir seus alunos a refletir sistematicamente sobre os recursos composicionais e expressivos mais usuais nos diversos gêneros textuais escritos.

Conforme Costa Val (p. 93-94),

Aprender a escrever envolve aprender a construir uma imagem adequada do leitor pretendido e das condições em que se prevê a realização da leitura - o suporte, a situação imediata, o contexto histórico, social, político e ideológico -, e se orientar por essas representações no controle da articulação, distribuição e explicitude das informações (entre outras coisas), durante o processo de produção do texto.

Ainda de acordo com a autora, o trabalho deliberado de composição textual é uma das coisas que os alunos precisam aprender para, efetivamente, aprender a escrever, e envolve, entre outros aspectos, a construção da superestrutura e da macroestrutura semântica, além da estruturação sintática dos enunciados. Por essa razão, o autor de um texto escrito precisa tomar decisões de várias ordens, devendo, para tanto, dispor de um repertório amplo de possibilidades de construção textual.

Costa Val destaca o fato de que, para os aprendizes da escrita, é difícil construir uma imagem adequada do leitor e das condições de leitura do texto que escrevem, visto que isso requer um grande esforço de descentramento e abstração, de deslocamento do presente concreto imediato. Além do mais, é possível que os aprendizes desconheçam muitos dos gêneros textuais escritos em circulação que lhes possam servir de referência no momento de produzir seus próprios textos, razão pela qual cabe à escola trabalhar, de forma sistemática e consistente, esses tipos de conhecimentos e habilidades.

Menegassi e Gasparotto (2016) também sustentam que a aprendizagem da escrita depende de ações sistemáticas e organizadas, entre as quais ocupa lugar privilegiado o trabalho de revisão e reescrita. Para eles, a revisão textual orientada pelo docente é uma etapa importante do processo de desenvolvimento das habilidades de escrita pelos discentes, representando um rico momento de troca, negociação e reflexão. Nessa perspectiva, a qualidade da reescrita está intrinsecamente ligada à efetividade da revisão.

Numa visão semelhante, Gonçalves (2010) propõe ampliar a concepção de correção de texto, tradicionalmente vista como uma atividade isolada em que o professor apenas marca os erros cometidos pelos alunos em seus textos. Levando em conta a natureza mediadora do outro na construção dos sentidos, o autor sugere que, no processo de ensino-aprendizagem-avaliação da escrita, seja criada uma rede de atividades organizadas e sistematizadas, nas quais se utilizem diversos instrumentos em diferentes momentos da cadeia de produção textual. 
Gonçalves diz que a releitura, a revisão e a reescrita - partes integrantes da escrita - constituem momentos fortes da aprendizagem da produção de um texto e são atividades que também se aprendem. Daí a importância de o professor fazer mediações adequadas, construindo comentários dialógicos pertinentes e precisos, que podem trazer grande contribuição ao processo de produção de sentidos. Para tanto, é possível criar o que o autor chama de lista de controle ou de constatações, que os alunos tomariam como referencial no trabalho de revisão e reescrita textual. Essa lista de controle favorece a retomada dos conceitos-chave desenvolvidos e cria uma espécie de linguagem comum acerca do gênero textual que esteja sendo objeto do processo de produção.

Um exemplo citado por Gonçalves diz respeito à produção de um resumo acadêmico, para cuja avaliação foram traçados quatro grandes tipos de questões:

(1) questões relativas ao contexto de produção;

(2) questões relativas à organização geral do texto;

(3) questões relativas à textualização e

(4) questões relativas à microestrutura textual.

Cada grande tipo de questão se desdobra em um detalhamento próprio. Assim, no caso da textualização, o aluno teria que avaliar se seu texto atende a critérios específicos do gênero textual, tais como:
a) foram usados verbos de elocução para referir-se ao discurso de outrem?
b) a voz do autor foi diferenciada da voz do produtor do resumo?
c) foram utilizados organizadores lógico-discursivos adequados?
d) foram evitadas expressões repetitivas e desnecessárias?

Esse processo de retomada do texto por meio de intervenções interativas, conforme o autor, permite um maior desenvolvimento da heterogeneidade do discurso, ao tempo em que favorece a construção, por parte dos alunos, de conhecimentos adequados e necessários à prática de escrita.

Para Conceição (2002), é preciso levar os alunos a assumir uma atitude de atenção aos seus textos, despertando neles interesse por produzir deliberados efeitos de sentido sobre os interlocutores. Desse modo, seria assegurada a discursividade da escrita, para o que é fundamental promover interações entre alunos, professores e textos. A autora sustenta que a escrita se funda em cinco princípios:

(1) o texto é passível de publicação (de tornar-se coisa pública);

(2) todo texto é resposta a outro texto, uma proposta de diálogo;

(3) a constituição do texto deve levar em conta, primeiramente, para quem e para que escrever;

(4) a escrita é um processo e deve-se escrever quantas vezes for necessário;

(5) todo texto deve apresentar qualidades discursivas que determinam a qualidade da interlocução.

Nesse sentido, o aluno deve se preocupar menos com os modelos canonizados de redação escolar e buscar as qualidades discursivas do texto. No caso da argumentação, tema deste estudo, é importante investir no convencimento e/ou na persuasão do interlocutor, articulando de forma eficaz os sentidos particulares propostos pelo autor com os sentidos particulares trazidos pelo leitor.

Outro estudo importante para nossa discussão é o de Schneider e Sella (2013). Para as autoras,

conceber o ensino da língua como vinculado às práticas sociais e à sua utilização como instrumento efetivo de interação entre os indivíduos requer levar o aluno a entender que existem recursos disponíveis no sistema de uma língua que servem ao escritor e ao leitor, na constituição dos sentidos dos enunciados, sejam eles escritos ou orais (p. 5). 
Assim, quando se trata da produção textual, para que o aluno possa se posicionar na escrita como sujeito/autor de seu texto, é necessário subsidiá-lo com conhecimentos sobre esses recursos linguísticos, tornando-o consciente de seu papel específico na condução da argumentação.

Mais algumas ações didáticas podem ser adotadas no sentido de desenvolver nos alunos capacidades adequadas à escrita do texto argumentativo, como, por exemplo, as citadas por Riolfi e Igreja (2010, p. 322):

Cotejamento de textos argumentativos diversos, visando depreender quais são as partes variáveis e invariáveis desse gênero; a reflexão a respeito da existência de coerência entre cada tese e seu respectivo argumento; a montagem de 'enciclopédias' de uso comum para a composição de textos argumentativos; a introdução de argumentos, em forma de citação, nos lugares mais adequados de textos previamente preparados pelo professor etc.

Um último artigo que achamos relevante mencionar neste item é o de Suassuna (2017), que tratou especificamente dos critérios de avaliação. A autora entende que os critérios são a base de uma avaliação formativa autêntica e teriam o papel de ajudar os aprendizes a desenvolver capacidades críticas diante de seus próprios conhecimentos sobre a escrita. Ademais, a um só tempo, "auxiliam o professor a selecionar aspectos e fenômenos pertinentes para o encaminhamento da análise textual, a planejar a mediação didática a ser feita e a definir/hierarquizar os problemas a serem tratados" (SUASSUNA, 2017, p. 279) e "auxiliam o aluno na análise e na regulação da tarefa de escrita, bem como na verificação da própria atuação no projeto discursivo que pretendeu realizar" (p. 279).

Em suma, defendemos que as situações de produção de textos sejam significativas para os alunos; que se originem de temas e contextos interativos nos quais eles estejam imersos; que lhes possibilitem se constituírem como sujeitos autores dos seus próprios discursos. Tudo isso requer um trabalho processual, o qual envolve interações, contextos polifônicos de produção, retomadas dos escritos e ações planejadas.

\section{Fundamentos Metodológicos}

Esta pesquisa, de natureza descritiva (GIL, 2008)² e exploratória (OLIVEIRA, 2016) ${ }^{3}$, objetivou apresentar alguns aspectos teórico-metodológicos implicados no ensino da produção escrita de textos argumentativos, a partir de estudos empíricos que discutem essa questão e da análise de produções escritas de alunos do ensino médio.

O corpus é constituído por textos dissertativo-argumentativos produzidos por dois estudantes do $3^{\circ}$ ano do ensino médio de uma escola da rede pública estadual de Pernambuco. Esses textos integram o conjunto de dados de uma dissertação de mestrado intitulada A Produção Escrita de Textos Argumentativos: reflexões sobre prática docente e aprendizagem de alunos (CAMPOS, 2012), desenvolvida no âmbito do Programa de Pós-graduação em Educação da Universidade Federal de Pernambuco.

Nessa investigação, o foco recaiu sobre a prática docente e o ensino da argumentação, observando-se de que forma as orientações dadas por professores de língua portuguesa para a produção de texto argumentativo, no ensino médio, eram indiciadas nos textos dos alunos. O referido trabalho foi viabilizado após assinatura, pela pesquisadora e pelos colaboradores, de um Termo de Consentimento Livre e Esclarecido (TCLE), no qual constavam informações sobre as especificidades da pesquisa (objeto de estudo, objetivos, métodos de coleta e tratamento de dados, e resultados esperados), assim como sobre os possíveis riscos que se

\footnotetext{
2 Para Gil (2008), as pesquisas descritivas têm por finalidade analisar as características de um fenômeno, tentando identificar as variáveis que se relacionam com ele.

${ }^{3}$ De acordo com Oliveira (2016), a pesquisa exploratória envolve estudos que proporcionam uma visão geral do fato ou fenômeno estudado.
} 
poderia proporcionar aos participantes, a prerrogativa de que os sujeitos poderiam se retirar do estudo a qualquer momento e a garantia do seu anonimato em qualquer situação.

Participaram dessa investigação duas professoras de língua portuguesa da rede pública estadual de Pernambuco, selecionadas por meio de critérios definidos na pesquisa. Como métodos de coleta de dados, foram adotadas a observação de aulas de língua portuguesa em turmas de $3^{\circ}$ ano do ensino médio, com registros em diário de campo, entrevistas semiestruturadas e a coleta dos textos (documentos) produzidos pelos estudantes no período observado.

No diário de campo, foram documentadas/acompanhadas as ocorrências das atividades de produção de texto, sendo registrados os aspectos que seriam pertinentes à pesquisa (formas de condução do professor, orientações dadas aos alunos, materiais utilizados nas aulas, utilização de um planejamento prévio para as aulas). Não constituíram interesse primordial dessa investigação as formas de avaliação adotadas pelas professoras frente aos textos produzidos, nem as sequências de atividades realizadas após a escrita propriamente dita.

Para este artigo, o recorte feito corresponde à análise das estratégias linguísticas e discursivas presentes em dois dos textos elaborados, por meio dos quais serão indicadas algumas possibilidades para o ensino da argumentação. Descrevemos a seguir a situação de sala de aula em que esses textos emergiram.

Quadro 1 - Descrição da aula de produção do texto argumentativo

1. A professora entra na sala e solicita que os alunos se dividam em grupos de 4 ou 5 componentes.

2. Entrega aos alunos jornais para a leitura de notícias do domingo anterior.

3. Os alunos devem escolher um texto e, após a leitura, socializar as suas impressões sobre cada um.

4. Quatro equipes fazem apresentação sobre os gêneros de texto lidos: (a) poesia; (b) crônica; (c) texto de opinião sobre a descriminalização da maconha; (d) texto informativo sobre a legalização da maconha.

5. Na mediação, a professora faz perguntas às equipes, tais como: qual a pertinência de cada tema para a sociedade? Qual o tema de cada texto? Que tipo de texto vocês leram? Que tipo de linguagem era predominante em cada texto? O que cada um de vocês achou do texto?

6. Verificando que o tema da legalização da maconha "rendeu" uma boa discussão, a professora pergunta a opinião deles sobre o tema em questão.

7. A professora chama a atenção dos alunos para os argumentos utilizados pelos organizadores dos últimos eventos acerca da legalização da maconha.

8. Os alunos começam a expor e defender suas ideias.

9. Há alunos que concordam com a legalização e, para justificar, apresentam alguns argumentos como: (a) todos têm direito à liberdade de escolha; (b) possibilidade de diminuir o tráfico; (c) as brigas entre as gangues que disputam o poder sobre as drogas não iriam mais existir.

10. Há, por outro lado, alunos que discordam, sob os argumentos: (a) a sociedade vai sofrer as consequências, pois haverá mais crianças dependentes; (b) liberando-se a maconha, serão liberados outros tipos de drogas; (c) o tráfico não vai acabar, porque nem sempre os viciados vão ter dinheiro para comprar a maconha e vão procurar outras drogas mais potentes; (d) ocupação de espaço público de forma indevida por fumantes de maconha, incentivando o uso dessa droga; (e) as pessoas não estão pensando nas consequências que a maconha traz para o organismo de quem é dependente dela; (f) esqueceram-se de pensar nas famílias que sofrem com os usuários de maconha.

11. Um dos alunos toma a palavra e se expressa alertando a turma de que o problema não é a maconha e, sim, as flores e folhas dessa erva, que tem nome científico de Cannabis sativa. Segue, informando que a maconha pode ser fumada ou ingerida em forma de bebida e que, na maioria das vezes, é usada para causar sensação de alívio. O aluno acredita que quem usa a maconha faz isso para fugir da realidade. Lembra, porém, que o uso repetitivo da erva pode causar dependência química e levar à morte. Diz que uma das características do usuário de maconha é a falta de vontade de se cuidar e de cuidar de sua higiene. Registra que, de acordo com a Organização das Nações Unidas (ONU), entre os anos de 2006 e 2007, houve um aumento de 8 milhões de usuários (população adulta) de maconha.

12. Os colegas aplaudem esse aluno e dizem que ele "está com tudo". Ele sorri e diz que leu essas informações numa revista sobre o assunto.

13. Nesse instante, a professora se posiciona, dizendo que também é contra a legalização da maconha, lembrando a dificuldade de, no Brasil, as pessoas seguirem regras.

14. Comenta, então, que irá propor a produção de um texto dissertativo-argumentativo sobre o último tema que foi discutido.

15. No quadro, ela registra o seguinte trecho: "Todos os direitos da humanidade foram conquistados pela luta..." (VON IHERING).

16. Ela explica que o trecho é para que eles reflitam um pouco mais sobre o tema que acabaram de debater. 
17. Lembra aos alunos a estrutura do texto dissertativo (introdução, desenvolvimento e conclusão), assim como, a distribuição de parágrafos em cada uma das partes.

18. Os alunos perguntam sobre a quantidade de linhas.

19. A professora informa que o texto deverá ter entre 20 e 25 linhas e deverá ser entregue a ela ao final da aula.

20. Os alunos começam a produzir os seus textos.

21. A aula se encerra, os alunos destacam as folhas com as suas produções e entregam à professora.

Fonte: Campos, 2012, p. 107-108.

\section{Análise dos Textos Argumentativos Produzidos}

Como dito, a partir da aula acima descrita, foram produzidos os dois textos que servirão à discussão proposta neste artigo, a qual enfocará as operações de escrita realizadas pelos alunos, associadas a algumas proposições metodológicas.

\section{Texto Argumentativo 1}

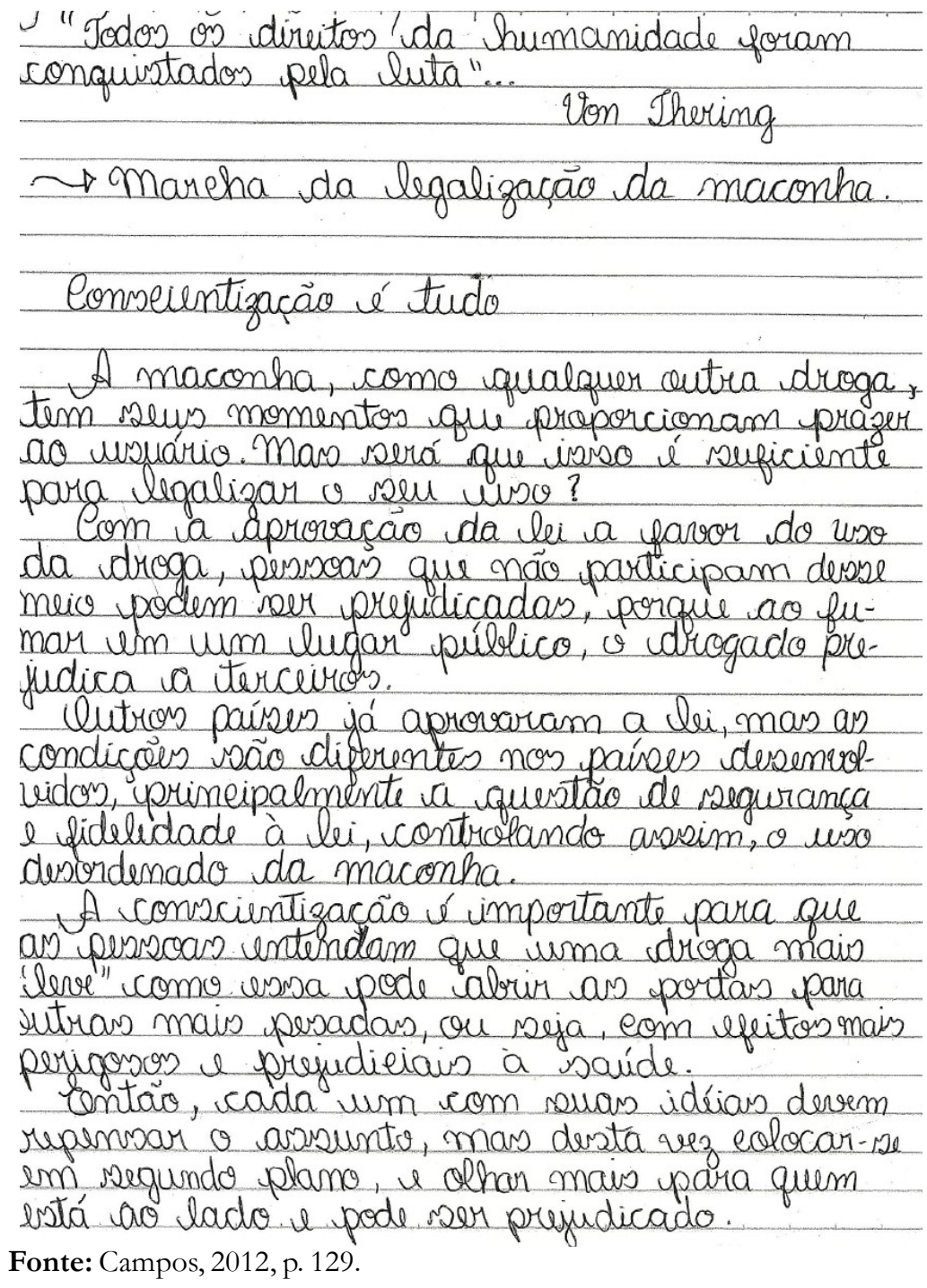

Figura 1 - Texto argumentativo 1

Verificamos que o aluno construiu um texto dentro da temática proposta e que, de certo modo, pode ser caracterizado como argumentativo. Seguindo as orientações dadas pela professora, fez um esforço de 
construção de argumentos em defesa de sua tese, usando para isso, inclusive, uma pergunta retórica. Depreendese, a partir de algumas pistas, que a argumentação foi desenvolvida de acordo com o seguinte esquema geral:

TESE: A maconha não deve ser legalizada.

ARGUMENTO: $O$ usuário de maconha prejudica terceiros.

CONTRA-ARGUMENTO A SER REFUTADO: A maconha proporciona prazer ao usuário.

CONCLUSÃO: O direito dos que não usam a maconha está acima do prazer do usuário.

No entanto, o aluno não conseguiu desenvolver sua argumentação de forma qualificada e convincente, por várias razões, que passamos a enumerar.

(1) Não ficou bem estabelecida a relação entre título e texto; na verdade, o autor abriu o texto com uma epígrafe (frase sugerida pela professora), referiu-se à marcha pela legalização da maconha (que era o tema da notícia lida antes) e depois inseriu a frase Conscientização é tudo (provavelmente antecipando o argumento final).

(2) Os argumentos citados são parcialmente pertinentes e suficientes para a defesa da tese.

(3) Em termos de seleção/coerência lexical, pelo uso dos hiperônimos droga/drogado, o aluno produziu um discurso genérico, não sendo bem-sucedido na retomada de certos termos.

(4) O argumento trazido no terceiro parágrafo - o fato de alguns países já terem legalizado o uso da maconha não pode ser considerado aqui no Brasil, pois não somos uma nação desenvolvida não foi apresentado de modo consistente, o que enfraqueceu a refutação de um contra-argumento possível.

(5) No quarto parágrafo, o autor introduz o elemento conscientização para se referir ao risco de o uso da maconha, considerada mais leve, poder conduzir a drogas mais pesadas, de efeitos mais perigosos; note-se que aqui, da mesma forma como ocorreu no terceiro parágrafo, a questão do prejuízo de terceiros não aparece, e a consciência parece ter sido evocada apenas para alertar para os riscos crescentes do uso da maconha.

(6) O final do texto corresponde a uma solução simplista e, ao mesmo tempo, contraditória - o autor admite que cada um pode ter suas ideias, recomenda repensar o assunto e determina que os usuários da maconha se coloquem em segundo plano e olhem mais para quem está ao lado e pode ser prejudicado.

(7) A epígrafe contradiz o texto, na medida em que afirma que todos os direitos da humanidade foram conquistados à custa de luta. Se considerarmos que a marcha pela legalização da maconha visa à conquista do direito ao uso livre (não criminalizado, portanto) da maconha, a manutenção da ilegalidade não representa direito, e os que condenam o uso não têm por que lutar.

(8) O texto revelou problemas no uso dos conectores e demais recursos de coesão textual, que prejudicam a continuidade e a progressão das ideias, além de algumas falhas no manuseio da variedade culta da língua.

Diante desse texto, nossa tarefa, enquanto professores responsáveis pelo ensino da escrita, seria, independentemente de posições pessoais assumidas a respeito da temática, colaborar para que o aluno fosse mais bem-sucedido no propósito de expor sua tese e convencer seus interlocutores a não se posicionarem em defesa da legalização da maconha.

Pelo que foi colocado até aqui sobre o ensino, a aprendizagem e a avaliação da produção escrita na escola, em particular do texto argumentativo, vários conteúdos e procedimentos didáticos poderiam compor as aulas subsequentes à produção do texto analisado. Sugerimos, por exemplo: 
(1) identificar o leitor presumido, bem como o objetivo central do texto;

(2) identificar a tese - o prazer advindo do uso da droga não deveria ser tomado como base para a sua legalização - e reafirmar ou não a sua escolha;

(3) identificar os argumentos trazidos para o texto - prejuízo de terceiros / adoção da medida da legalização por outros países / risco de a maconha ser a porta para o uso de drogas mais pesadas - e avaliá-los em termos de pertinência e suficiência;

(4) rever a atribuição do título ao texto, avaliando os efeitos de sentido da epígrafe;

(5) discutir as ocorrências de discurso reportado e de argumento de autoridade;

(6) observar o uso de conectores oracionais e demais operadores discursivos;

(7) atentar para as modalizações;

(8) juntamente com a revisão dos argumentos, equilibrar a progressão e a continuidade temática;

(9) levantar e avaliar os contra-argumentos possíveis, para refutá-los de forma adequada e convincente;

(10) avaliar o grau de informatividade e novidade do texto;

(11) fazer um levantamento de algumas estratégias argumentativas usadas, verificando seus efeitos sobre a argumentação (aspas, pergunta retórica);

(12) ler outros textos argumentativos, cujos autores se colocam contra a legalização da maconha, atentando para os argumentos construídos; em seguida, procurar selecionar alguns desses argumentos e tentar incorporá-los ao texto original, avaliando os resultados das escolhas.

\section{Texto Argumentativo 2}

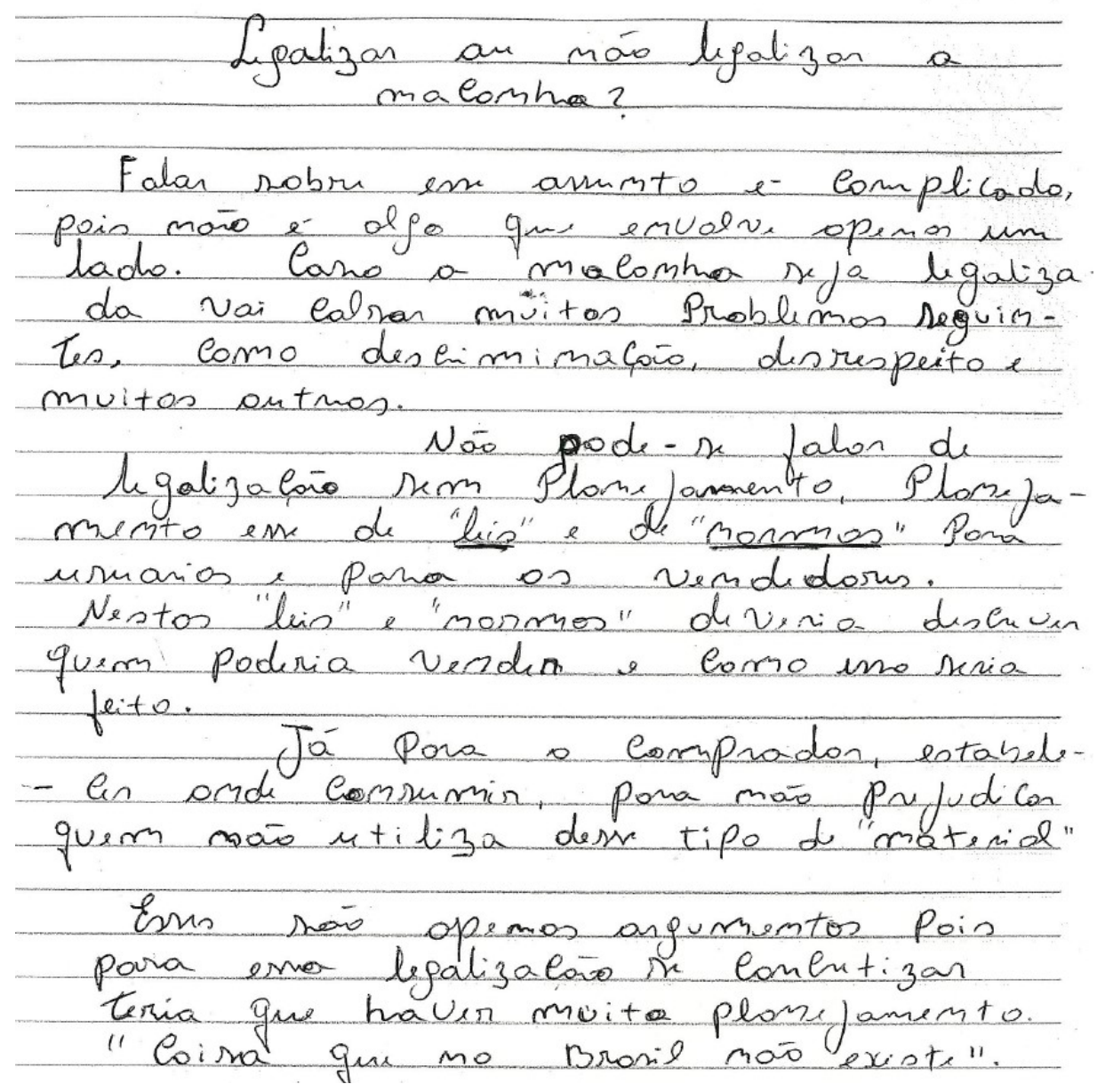

Fonte: Campos, 2012, p. 131.

Figura 2 - Texto argumentativo 2 
O aluno 2, participante do mesmo evento de aula, segue a estrutura composicional sugerida em aula (introdução, desenvolvimento e conclusão), atendendo à orientação sobre o quantitativo de parágrafos definidos como o ideal para a dissertação argumentativa. De certa forma, poderíamos sintetizar a estrutura de seu texto assim:

TESE: A maconha não deve ser legalizada.

ARGUMENTO: Deve haver planejamento a fim de que sejam evitados problemas para usuários, vendedores e não usuários de maconha

CONTRA-ARGUMENTO A SER REFUTADO: No Brasil, não existe planejamento adequado para regrar a vida social.

CONCLUSÃO: Para a legalização se concretizar, primeiro, deve haver planejamento consistente.

Numa análise mais detalhada, alguns aspectos merecem atenção:

(1) O aluno produz um texto argumentativo, embora mostre limitações para apresentar um repertório de ideias consistentes para a defesa de seu ponto de vista. Segundo dados da pesquisa original (cf. CAMPOS, 2012), o produtor desse texto mereceu destaque, nas anotações da pesquisadora, por ser responsável pelo episódio 11 (ver descrição de aula no Quadro 1 deste artigo). Em outras palavras, o estudante, no debate oral proposto e mediado pela professora, produziu vários discursos sobre o tema da maconha, desvelando o caráter polifônico da argumentação, mas não conseguiu transpor seus argumentos para o texto escrito.

(2) O título do texto, que é uma pergunta sobre o tema, anuncia uma certa insegurança do aluno para abordar a questão, aspecto que é demonstrado logo no início do primeiro parágrafo: Falar sobre esse assunto é complicado, pois não é algo que envolve apenas um lado.

(3) No segundo período do primeiro parágrafo, o aluno expõe seu ponto de vista: Caso a maconha seja legalizada vai calsar muitos problemas seguintes como descriminação, desrespeito e muitos outros. Aqui, verificamos problemas de inadequação linguística, que comprometem, parcialmente, o sentido do parágrafo.

(4) $\mathrm{Na}$ sequência, o estudante parece não conseguir extrapolar o argumento que usa para justificar o seu ponto de vista (Não pode-se falar de legalização sem planejamento, planejamento esse de "leis" e de "normas" para usuários e para os vendedores), ainda que, nos demais parágrafos, ele vá tentando destrinchar esse argumento.

(5) É possível observar que o autor do texto tem ideia de um interlocutor presumido (ou auditório), porque, ao mencionar a importância da criação de uma legislação específica para o uso da maconha, direciona-se ao usuário/comprador, ao vendedor e aos não consumidores dessa droga (ele usa a referenciação por meio da expressão desse material).

(6) Apesar de ser um texto que não aprofunda a temática, o aluno tenta desenvolver uma sequenciação, fazendo uso de conectores gramaticais e lexicais como o uso de esse, nesta, pois, já, coisa...

(7) $\mathrm{Na}$ sua conclusão, o autor reafirma seu posicionamento (para essa legalização se concretizar, teria que haver muito planejamento), mas, introduz um contra-argumento não esperado pelo leitor (coisa que no Brasil não existe). Essa quebra de expectativa, materializada no texto escrito, faz-nos pressupor que o aluno tem dificuldades para lidar com as estratégias do dizer, de forma a encadear argumentos e contra-argumentos no seu texto.

É nesses termos que, à semelhança do que fizemos com o texto 1, alguns procedimentos didáticos podem ser adotados antes e depois da produção. Assim, na etapa anterior à escrita do texto, é importante: 
(1) possibilitar que o aluno se assuma como locutor de seu texto, percebendo possíveis interlocutores;

(2) desenvolver estratégias para que o aluno tenha o que dizer, saiba como fazê-lo e tenha razões para fazê-lo;

(3) no momento do debate oral, registrar, no quadro, as diferentes posições e informações dos alunos, potencializando as tomadas de posição, de argumentação e de refutação de argumentos;

(4) a partir da leitura e compreesnsão de outros textos argumentativos, explorar as especificidades dos processos/mecanismos de textualização no discurso oral e no discurso escrito.

Já nos momentos posteriores à produção textual, recomendaríamos:

(1) levar os alunos a reconhecer e analisar estratégias básicas presentes nos textos argumentativos produzidos;

(2) chamar atenção para formas de utilização de recursos linguísticos e organização do discurso por diferentes autores que tratem do mesmo tema da dissertação argumentativa, analisando aproximações e distanciamentos das estratégias usadas pelos alunos.

(3) explorar os mecanismos discursivos empregados com vistas à adesão de interlocutores nos textos argumentativos;

(4) ler e reler os textos dos alunos, incentivando a revisão e a reescrita das produções.

Essas são apenas algumas ideias dentre muitas outras possibilidades de encaminhamento didático a se adotar nos casos aqui estudados. Nossa intenção, ao propô-las, foi destacar a importância das mediações para a aprendizagem dos alunos, que muito têm a dizer e, nessa perspectiva, devem ter assegurado o seu direito ao dizer, e aos conhecimentos e saberes implicados no dizer.

\section{Conclusão}

Este nosso estudo teve por objetivo levantar algumas questões acerca da escrita do texto argumentativo no ensino médio, problematizando seu ensino a partir de pesquisas e estudos que tratam dessa temática e que apontam a baixa frequência de escrita sistemática, em aulas de língua portuguesa, bem como a superficialidade dos contextos de produção na escola.

Nessa direção, vários fenômenos do processo de ensino-aprendizagem do texto argumentativo aqui descritos são dignos de destaque. Um deles é que os alunos, mesmo que tenham levantado bons argumentos em discussões orais sobre temas controversos que comumente antecedem o momento da feitura da dissertação, não conseguem transpô-los para suas produções escritas. Já estando na etapa final da educação básica, ainda demonstram diversos problemas no trato com o texto argumentativo, tais como: falta de domínio das especificidades da modalidade escrita da língua; dificuldade de adequação ao tema; imprecisão de informações; incoerência semântica; baixo nível de informatividade; generalizações indevidas; falhas na estrutura e no encadeamento lógico de ideias; dificuldade nas tomadas de posição e de movimentos de sustentação e refutação de argumentos, entre outros.

É fato que muitos professores têm-se apropriado da ideia de que é importante trabalhar com as diversas habilidades que podem levar os alunos a produzirem textos argumentativos e até concebem a argumentação como forma de persuasão, de ação sobre os outros; entretanto, há, ainda, alguns entraves para o ensino desse gênero textual que precisam ser problematizados em busca de uma ação docente diferenciada.

Nesse sentido, as ações aqui propostas visam a contribuir com o debate sobre o ensino da argumentação, pressupondo que, por meio de orientações didáticas consistentes e constantes, a argumentação em espaços escolares possa ser uma ação de linguagem integrante do processo de ensino-aprendizagem de língua portuguesa. 
Pensamos, então, que uma efetiva ação do professor de língua portuguesa que subsidie o aluno com conhecimentos sobre os recursos linguísticos a seu dispor e que o ajude na tomada de consciência de seu papel na condução de uma argumentação eficaz é fundamental para que o ele se posicione na escrita como sujeito-autor de seu texto.

\section{REFERÊNCIAS}

BRETON, P. A argumentação na comunicação. Tradução Viviane Ribeiro. 2. ed. São Paulo: EDUSC, 2003.

CAMPOS, A. de S. A produção escrita de textos argumentativos: reflexões sobre prática docente e aprendizagem de alunos. 2012. Dissertação (Mestrado) - Universidade Federal de Pernambuco, Recife, 2012.

CITELLI, A. O texto argumentativo. São Paulo: Scipione, 1994.

CONCEIÇÃO, R. I. S. O ensino da produção textual e a (re)construção da competência discursiva do aluno. Trabalhos de Lingüistica Aplicada, Campinas, n. 40, p. 45-61, jul./dez. 2002.

COSTA VAL, M. da G. O desenvolvimento do conhecimento linguístico-discursivo: o que se aprende quando se aprende a escrever? Veredas, Juiz de Fora, v. 5, n. 1, p. 83-104, 2009.

CRUZ, M. C. As condições de produção do texto no ensino médio. Revista Ecos, Cáceres, n. 7, p. 75-82, dez. 2008.

GERALDI, J. W. Portos de passagem. 4. ed. São Paulo: Martins Fontes, 2003.

GIL, A. C. Métodos e técnicas de pesquisa social. 6. ed. São Paulo: Atlas, 2008.

GONÇALVES, A. V. Gêneros textuais e reescrita: uma proposta de intervenção para o ensino de língua materna. Linguagem em (Dis)Curso, Palhoça, v. 10, n. 1, p. 13-42, jan./abr. 2010.

GREGOLIN, M. do R. V. Lingüística textual e ensino de língua: construindo a textualidade na escola. Alfa, São Paulo, v. 37, p. 23-31, 1993.

KOCH, I. G. V. O texto e a construção dos sentidos. 10. ed. São Paulo: Contexto, 2011.

KOCH, I. G. V.; ELIAS, V. M. Escrever e argumentar. São Paulo: Contexto, 2017.

LEAL, T. F.; MORAIS, A. G. A argumentação em textos escritos: a criança e a escola. Belo Horizonte: Autêntica, 2006.

MENEGASSI, R. J.; GASPAROTTO, D. M. Revisão textual-interativa: aspectos teórico-metodológicos. Dominiosde Lingu@gem, Uberlândia, v. 10,n. 3, p. 1019-1045, jul./set. 2016.

OLIVEIRA, M. M. Como fažer pesquisa qualitativa. 7. ed. Petrópolis: Vozes, 2016.

PÉCORA, A. Problemas de redação. 5. ed. São Paulo: Martins Fontes, 1999.

PERELMAN, C.; OLBRECHTS-TYTECA, L. Tratado da argumentação: a nova retórica. Tradução Maria Ermantina G. Pereira. 2. ed. São Paulo: Martins Fontes, 2005. 
RIOLFI, C. R.; IGREJA, S. G. Ensinar a escrever no ensino médio: cadê a dissertação? Educaşão e Pesquisa, São Paulo, v. 36, n. 1, p. 311-324, jan./abr. 2010.

SAVIOLI, F. P.; FIORIN, J. L. Lições de texto: leitura e redação. 4. ed. São Paulo: Ática, 2001.

SCHNEIDER, G. T.; SELLA, A. F. O processo de produção textual escolar mediado pela análise linguística com enfoque na argumentação. Linguas \& Letras, Cascavel, v. 14, n. 26, p. 1-15, 2013.

SOUZA, L. V. As proezas das crianças em textos de opinião. São Paulo: Mercado de Letras, 2003.

SUASSUNA, L. Avaliação da escrita escolar: a importância e o papel dos critérios. Educar em Revista, Curitiba, v. 33, n. 66, p. 275-293, out./dez. 2017.

XAVIER, A. C. Como fazerer e apresentar trabalhos cientificos. Recife: Rêspel, 2010. 